\title{
Lesson of the month 2: Houssay phenomenon- hypopitutarism leading to remission of diabetes
}

\author{
Authors: Subhodip Pramanik, ${ }^{A}$ Rana Bhattacharjee, ${ }^{B}$ Pradip Mukhopadhyay ${ }^{C}$ and Sujoy Ghosh ${ }^{\text {D }}$
}

Because of a pituitary insult and the subsequent loss of counter-regulatory hormones, individuals can experience increased sensitivity to insulin, hypoglycaemia or even complete amelioration of diabetes; this is known as the Houssay phenomenon. Severe dehydration following diarrhoea can lead to pituitary infarction causing hypopituitarism. We describe this situation in a patient with insulin-treated type- 2 diabetes presenting with recurrent hypoglycaemia and cessation of insulin requirement along with weight loss, hypotension and hyponatraemia. Pituitary imaging revealed a partial empty sella and a synacthen stimulation test revealed an initial positive response but later loss of response, proving recent-onset pituitary dysfunction. Physicians should keep this possibility in mind while treating hypoglycaemia in stable diabetic individuals. Judicious supplementation of deficient hormones is of utmost importance.

KEYWORDS: Hypoglycaemia, cortisol deficiency, diarrhoea, hyponatremia, Houssay

\section{Case presentation}

A 42-year-old non-smoker, teetotal male, known to be suffering from type-2 diabetes for 12 years (had been on insulin for the last 4 years) presented with recurrent hypoglycaemia leading to gradual reduction of insulin doses and, ultimately, cessation of insulin therapy for a month prior to presentation. He had suffered from a diarrhoeal illness with severe dehydration 1 month previously for which he required hospital admission for intravenous rehydration. He reported significant weight loss $(\sim 11 \mathrm{~kg})$, lethargy, nausea, and generalised weakness since his

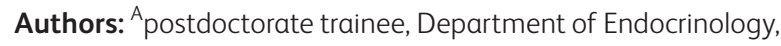
Institute of Post-Graduate Medical Education and Research, Kolkata, India; ${ }^{B}$ resident medical officer cum clinical tutor, Department of Endocrinology, Institute of Post-Graduate Medical Education and Research, Kolkata, India; ${ }^{C}$ associate professor, Department of Endocrinology, Institute of Post-Graduate Medical Education and Research, Kolkata, India; ${ }^{\text {D }}$ associate professor, Department of Endocrinology, Institute of Post-Graduate Medical Education and Research, Kolkata, India diarrhoeal illness. After experiencing recurrent hypoglycaemia and hypotension, his insulin and antihypertensive therapy was stopped (normally on 43 units NPH insulin per day, and metformin $1 \mathrm{~g}$, olmesartan $20 \mathrm{mg}$ and amlodipine $5 \mathrm{mg}$ before this episode). There was no history of postural dizziness, increased pigmentation, erectile dysfunction, loss of libido, cold intolerance or polyuria.

On examination, he was not overweight (body mass index $24.5 \mathrm{~kg} / \mathrm{m}^{2}$ ) and his blood pressure was $120 / 80 \mathrm{mmHg}$ without any postural drop. Pallor and oedema were absent. He was afebrile, there was no obvious pigmentation, no abdominal mass, and visual fields confrontation perimetry was normal. Laboratory investigation values were as follows (summarised in Table 1): haemoglobin $10.5 \mathrm{~g} / \mathrm{dL}$ (normal range 13-15 g/dL), creatinine $1.2 \mathrm{mg} / \mathrm{dL}$ (estimated glomerular filtration rate $81.4 \mathrm{~mL} / \mathrm{min} / 1.73 \mathrm{~m}^{2}$ by modification of diet in renal disease formula), sodium $130 \mathrm{mEq} / \mathrm{L}$ (normal range 135-145 mEq/L), potassium $4.9 \mathrm{mEq} / \mathrm{L}$, and glycated haemoglobin $6.8 \%$. Liver function was also normal. Electrocardiogram showed lateral wall ischaemia. His fasting self-monitoring of blood glucose values were near normal. Ultrasound of the kidneys demonstrated normal corticomedullary differentiation. Routine investigations at his last outpatient visit (2 months before) revealed similar renal function. Therefore, investigations ruled out deteriorating renal function/liver function as a cause of recurrent hypoglycaemia in this patient.

Hypoglycaemia can also occur because of deficiencies in hormones that prevent or reverse hypoglycaemia, such as cortisol, adrenaline, glucagon and growth hormone. Our initial endocrine profile revealed a low normal cortisol $6.5 \mu \mathrm{g} / \mathrm{dL}$ (normal range 5-25 $\mu \mathrm{g} / \mathrm{dL}$ ) and adrenocorticotropic hormone (ACTH) $4.2 \mathrm{pg} / \mathrm{mL}$ (normal range $5-46 \mathrm{pg} / \mathrm{mL}$; at $8 \mathrm{AM}$ ) leading to a suspicion of secondary adrenal insufficiency. Detailed evaluation of other pituitary hormones were performed: free thyroxin (T4) $1.1 \mathrm{ng} / \mathrm{dL}$ (normal range $0.8-1.8 \mathrm{ng} / \mathrm{dL}$ ), thyroid stimulating hormone (TSH) $1.8 \mu \mathrm{IU} / \mathrm{mL}$ (normal range $0.4-4.5 \mu \mathrm{IU} / \mathrm{mL}$ ), insulin like growth factor-1 (IGF-1) $158 \mathrm{ng} / \mathrm{mL}$ (normal range $56-201 \mathrm{ng} / \mathrm{mL}$ ), testosterone $423 \mathrm{ng} / \mathrm{dL}$ (normal range $200-820 \mathrm{ng} / \mathrm{dL}$ ) and prolactin $6 \mu \mathrm{g} / \mathrm{L}$ (normal range 2.5-17 $\mu \mathrm{g} / \mathrm{L}$ ). Magnetic resonance imaging (MRI) demonstrated partial empty sella with thinned out pituitary tissue anchored in the floor of the sella (Fig 1). Short synacthen test was performed during his admission with $250 \mu \mathrm{g}$ synthetic ACTH (tetracosactide) intramuscular given in the left deltoid, which increased serum 
Table 1. Investigations before, at and 6 weeks after presentation.

\begin{tabular}{|c|c|c|c|}
\hline Tests & $\begin{array}{l}2 \text { months before } \\
\text { admission }\end{array}$ & At admission & $\begin{array}{l}6 \text { weeks after } \\
\text { admission }\end{array}$ \\
\hline Haemoglobin, g/dL & 11.2 & 10.5 & \\
\hline Creatinine, mg/dL & 1.2 & 1.2 & \\
\hline Urine ACR, $\mu \mathrm{g} / \mathrm{mg}$ & 212 & & \\
\hline HBA1c, \% & 6.7 & 6.8 & \\
\hline Retinopathy & Mild NPDR in both eyes & & \\
\hline $\mathrm{Na} / \mathrm{K}, \mathrm{mEq} / \mathrm{L}$ & & $130 / 4.9$ & \\
\hline Lipid profile LFT & & WNL & \\
\hline ECG & & Lateral wall ischaemia & \\
\hline 8 am serum cortisol, $\mu \mathrm{g} / \mathrm{dL}$ & & 6.5 & 4.5 \\
\hline $\mathrm{ACTH}, \mathrm{pg} / \mathrm{mL}$ & & 4.2 & 4.0 \\
\hline $\mathrm{FT} 4, \mathrm{ng} / \mathrm{dL}$ & & 1.1 & 1.04 \\
\hline $\mathrm{TSH}, \mu \mathrm{IU} / \mathrm{mL}$ & & 1.8 & 2.1 \\
\hline Testosterone, ng/dL & & 423 & 220 \\
\hline Prolactin, $\mu \mathrm{g} / \mathrm{dL}$ & & 6 & 4.2 \\
\hline IGF-1, ng/mL & & 158 & 152 \\
\hline $\begin{array}{l}\text { Cortisol after short synacthen stimulation, } \\
\mu \mathrm{g} / \mathrm{dL}\end{array}$ & & 20.2 & 7.3 \\
\hline MRI brain & & $\begin{array}{l}\text { Partial empty sella with thinned out pituitary } \\
\text { tissue anchored in the floor of the sella }\end{array}$ & \\
\hline
\end{tabular}

ACR = albumin creatinine ratio; $\mathrm{ACTH}=$ adrenocortical trophic hormone; $\mathrm{ECG}=$ electrocardiogram; FT4 = free thyroxin, HBA1c = glycated haemoglobin; IGF1 = insulinlike growth factor $1 ; \mathrm{K}=$ potassium; $\mathrm{LFT}=$ liver function test; $\mathrm{MRI}=$ magnetic resonance imaging $=\mathrm{Na}=$ sodium; $\mathrm{NPDR}=$ nonproliferative retinopathy; $\mathrm{TSH}=$ thyroid stimulating hormone; $\mathrm{WNL}=$ within normal limit.

cortisol to normal range $(20.2 \mu \mathrm{g} / \mathrm{dL})$. We suspected acuteonset secondary adrenal insufficiency but the definitive test an insulin tolerance test - was not done as he had documented ischaemic heart disease and it was therefore contraindicated. The patient was discharged with amlodipine, atorvastatin, aspirin and stress dose of steroids with a plan for re-evaluation after 6 weeks.

Over the next 6 weeks he lost another $6 \mathrm{~kg}$, developed erectile dysfunction and postural dizziness and was not requiring antihyperglycaemic/antihypertensive therapy. On repeat

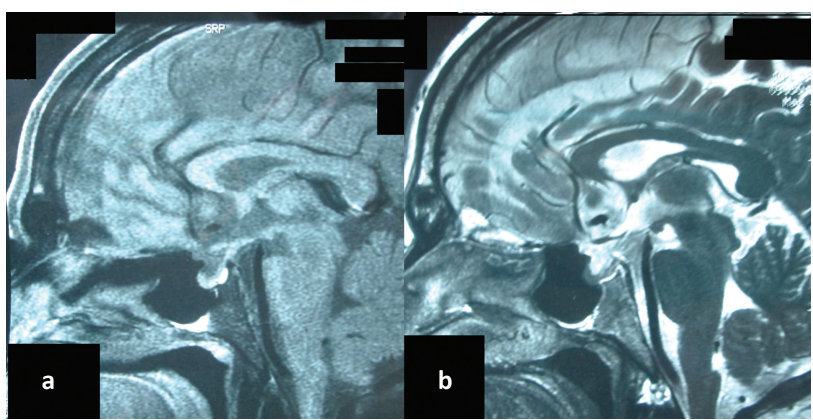

Fig 1. Magnetic resonance imaging hypothalamopituitary region shows a) T1W and b) T2W sagittal partially empty sella with thinned out pituitary tissue anchored in the floor of the sella. evaluation there was further decline in adrenal and gonadal axis with AM cortisol $4.5 \mu \mathrm{g} / \mathrm{dL}$, ACTH $4.0 \mathrm{pg} / \mathrm{mL}$, testosterone $220 \mathrm{ng} / \mathrm{dL}$, luteinising hormone $2.3 \mathrm{IU} / \mathrm{L}$, free T4 $1.04 \mathrm{ng} / \mathrm{dL}$, TSH $2.1 \mu \mathrm{IU} / \mathrm{mL}$, IGF-1 $152 \mathrm{ng} / \mathrm{mL}$ and prolactin $4.2 \mu \mathrm{g} / \mathrm{L}$. Repeat short synacthen test performed at this outpatient department visit was $7.3 \mu \mathrm{g} / \mathrm{dL}$ which clinched the diagnosis of secondary adrenal insufficiency.

He was started on hydrocortisone (10 mg AM and $5 \mathrm{mg}$ PM) and testosterone supplement (250 mg intramuscularly once a month) and followed up. However, during follow-up, his blood sugar and blood pressure began to rise and he was started on $\mathrm{NPH}$ insulin (18 units a day) and olmesartan $(20 \mathrm{mg})$ along with aspirin and statin and is currently doing well.

\section{Discussion}

Resolution of diabetes due to hypopituitarism was first documented in 1931, when the Argentinian Nobel laureate, Dr Bernardo Houssay, described this event in dogs. ${ }^{1}$ It was described in humans by Kotte et al in 1940 but seldom reported in the literature thereafter. ${ }^{2}$ It can occur following infarction/ haemorrhage (vascular cause) or following destructive lesion by tumours, although the latter is rare. ${ }^{3}$ In 1953, Williams described a diabetic pregnant lady with pituitary haemorrhage who developed extreme sensitivity to insulin and died of intractable hypoglycaemia. ${ }^{4}$ More recently, Zhang et al described a patient with a Rathke's cleft cyst leading 
to remission of diabetes status. ${ }^{5}$ In addition, deliberate, surgical hypophysectomy has been used for the treatment of diabetic retinopathy. A 1965 report in the British Medical Journal describes its use on 223 people with diabetes; with a successful reduction in incidence of $48 \%$ of subsequent retinal haemorrhage. ${ }^{6}$ This doesn't appear to have caught on.

There are many known causes of hypoglycaemia in patients with diabetes, namely reduced dietary intake, increased physical exercise, improper drug timing and deteriorating renal function. However, as stated above, deficiencies of cortisol, adrenaline, glucagon and growth hormones are also less common causes of recurrent hypoglycaemia. ${ }^{6}$ Hypopituitarism may occur after pituitary infarction following adenohypophyseal vasospasm during severe dehydration. This hypopituitarism could lead to recurrent hypoglycaemia ${ }^{6}$ like in our patient. This was supported by low ACTH, low cortisol and partial empty sella on MRI. This phenomenon has also been reported in postpartum pituitary infarction where hypopituitarism develops over months to years (Sheehan syndrome). ${ }^{7,8}$ Synacthen stimulation can lead to physiological increase in cortisol early in the course of secondary adrenal insufficiency, ${ }^{9}$ as in our case. However, the response is usually lost in 6 weeks, as lack of ACTH drive causes adrenal dysfunction. Apart from hypoglycaemia, cortisol deficiency can also cause hypotension, weight loss, lethargy, gastrointestinal symptoms and electrolyte abnormalities. ${ }^{10}$ Cortisol deficiency is associated with increased antidiuretic hormone secretion, which causes hyponatraemia ${ }^{5}$ as seen in our patient. Therefore, the presence of unexplained hyponatraemia should alert the clinician to this possibility.

\section{Learning points}

> Clinicians should be aware of cortisol insufficiency while evaluating recurrent hypoglycaemia in a stable individual with diabetes.

> Associated weight loss, lethargy, hypotension and hyponatremia are the clinical clues.
$>$ Synacthen stimulation test should be routinely done in cases with borderline cortisol deficiency.

> Other pituitary hormone evaluation is necessary in case of secondary adrenal insufficiency.

> Supplementation of deficient hormones is of utmost importance.

\section{Acknowledgements}

The authors thank Professor Subhankar Chowdhury for critical review of the manuscript.

\section{References}

1 Hadithi M, Toorians A, Heine R. The Houssay phenomenon, another clue to Sheehan's syndrome in a diabetic. Diabet Med 2002;19:795.

2 Kotte JH, Vonderahe AR. The Houssay phenomenon in man. JAMA 1940;114:950-3.

3 Drury MI, O'Loughlin S, Sweeney E. Houssay phenomenon in a diabetic. BMJ 1970;2:709.

4 Williams FW. Pituitary necrosis in a diabetic during pregnancy: the Houssay phenomenon in man. Diabetes 1952;1:37-40.

5 Zhang JTW, Ho KWK. Houssay phenomenon: a rare case of diabetes mellitus remission. Eur Diabetes Nursing 2011;8:115-6.

6 Harrold BP, Gough KR, Tulloh CG, Cates JE, Angell James J. Use of trans-sphenoidal hypophysectomy in diabetic retinopathy: preliminary assessment. Br Med J 1965;727-31.

7 Yen SSC. Chronic anovulation due to CNS-hypothalamic dysfunction. In: Yen SSC, Jaffe RB, Barbieri RL (eds), Reproductive endocrinology: physiology, pathphysiology, and clinical management, 4th edn. Philadelphia: Saunders, 1991: 516-61.

8 Kelestimur F. Sheehan's syndrome. Pituitary 2003;6:181-8.

9 Neary N, Nieman L. Adrenal insufficiency - etiology, diagnosis and treatment. Curr Opin Endocrinol Diabetes Obes 2010:17;217-23.

10 Samaan NA. Hypoglycemia secondary to endocrine deficiencies. Endocrinol Metab Clin North Am 1989;18:145-54.

Address for correspondence: Dr S Pramanik, Email: subhodip.mck@gmail.com

\section{Royal College of Physicians}

\section{Gifts and memorabilia}

In celebration of the latest RCP exhibition Scholar, courtier, magician: the lost library of John Dee (18 January - 29 July 2016), a range of gifts has been produced inspired by his work.

Mugs $£ 8$ (pictured)

Order by phone or online Tel $+44(0) 2030751358$ or emailpublications@rcplondon.ac.uk

See the full range of gifts at www.rcplondon.ac.uk/shop



